$\mathrm{A}$ lthough the concept of "bone quality" is at least 15 years old [1], the term has recently sparked much discussion and debate among clinicians and clinical researchers [2-5]. At a recent National Institutes of Health conference on bone quality, the term was defined as: "The sum total of characteristics of the bone that influence the bone's resistance to fracture" [6].

\section{Where Did the Definition Come From?}

This definition arose from the results of multicenter clinical trials that evaluated the effects of two classes of drugs-antiresorptive bisphosphonate therapy (alendronate and risedronate) and selective estrogen receptor modulator therapy (raloxifene)-on the prevention of osteoporotic fragility fractures $[7,8]$. While these studies reported consistent reductions in the incidence of fractures, the treatment effects could not be explained by contemporary changes in dual X-ray absorptiometric bone mineral density (BMD), the present clinical standard of bone fragility. These conflicting findings led to speculation that the antiresorptive drugs had additional skeletal effects upon a feature of the bone called "bone quality" [7-12].

The idea of bone quality, and the explanation for the conflicting results, linked together two important notions: (1) antiresorptive drugs acted by suppressing bone turnover through inhibiting bone resorption, and (2) increased bone turnover (mainly the increased bone resorption, as detected by bone markers) compromises the bone strength through deteriorated bone microarchitecture (a trait that cannot be captured by BMD measurement but could potentially be improved by antiresorptive treatment) [4].

Bone quality is now a widely embraced concept that seems to offer

The Essay section contains opinion pieces on topics of broad interest to a general medical audience. a solution to the classic paradox of osteoporosis: while low BMD values are associated with increased relative risk of fracture at the population level, the predictive value of BMD in an individual patient remains quite marginal [13-15]. And to further support the concept of bone quality, inclusion of increased bone turnover in fracture-predicting models has somewhat improved the ability to predict fracture risk independently of BMD [8,16-19].

\section{Flaws in the Concept}

Although the concept of bone quality might seem attractive for all of the reasons discussed above, nevertheless the notion has three major conceptual flaws.

\section{BMD and bone quality do not} explain fractures. First, although BMD indeed shows a strong correlation with whole bone strength in the laboratory setting ( $r$ up to 0.9 ) [20], in the clinical setting, paradoxically, the overall proportion of various fragility fractures attributable to low BMD (indicating reduced bone strength) remains modest (from $0 \%$ to $44 \%$ ) [15]. In other words, when looking at all types of fractures combined, over half occur among people who cannot be classified as having osteoporosis in the sense of the World Health Organization's operational definition of osteoporosis (BMD 2.5 standard deviations or more below the young adult reference level). In fact, BMD is only a modest risk factor for fractures; about $85 \%$ of the contribution to the fracture risk in general, or to the rise in fracture risk with age, is unrelated to BMD [15,21]. In other words, the concept of bone quality is invoked to explain fracture risk that cannot be attributed to BMD, but it seems impossible that bone quality could realistically explain $85 \%$ of all fractures.

BMD and bone quality are largely inseparable. Second, the concept of bone quality rests on a commonly held idea that BMD and bone quality would independently account for bone fragility in totality. But this idea is a fallacy. Basically, BMD reflects the bulk of material (bone mass) of which the bone, as an organ, is made [22]. BMD thus denotes a lumped measure of virtually everything within the measured bone site (i.e., bone crosssectional size and dimensions, cortical thickness and porosity, trabecular thickness and number, mineralization of bone material), but it denotes nothing specifically. Thus, there is not much left to be accounted for by subtle architectural and material properties (i.e., factors that allegedly account for bone quality). This simply means that BMD and most bone quality characteristics, measurable in vivo, are intertwined and largely inseparable.

Flaws in defining bone quality. Third, the definition of bone quality is too imprecise, incorporating a pool of "non-BMD" indices of bone fragility (or, even more broadly, the portion of fracture risk that is not predicted by BMD [6]). Neither do we have an established measurement, indicator, or unit for bone quality. We don't even have criteria for defining "good" or "bad" bone quality.

Funding: The authors received no specific funding for this article.

Competing Interests: The authors have declared that no competing interests exist.

Citation: Sievänen H, Kannus P, Järvinen TLN (2007) Bone quality: An empty term. PLoS Med 4(3): e27. doi:10.1371/journal.pmed.0040027

Copyright: $\odot 2007$ Sievänen et al. This is an open-access article distributed under the terms of the Creative Commons Attribution License, which permits unrestricted use, distribution, and reproduction in any medium, provided the original author and source are credited.

Abbreviations: BMD, bone mineral density

Harri Sievänen and Pekka Kannus are in the Bone Research Group, UKK Institute, Tampere, Finland. Pekka Kannus and Teppo L. N. Järvinen are in the Division of Orthopaedics and Traumatology, Department of Trauma, Musculoskeletal Surgery and Rehabilitation, Tampere University Hospital, Tampere, Finland. Teppo L. N. Järvinen is in the Department of Surgery and the Institute of Medical Technology, University of Tampere, Tampere, Finland.

* To whom correspondence should be addressed. E-mail: teppo.jarvinen@uta.fi 


\section{The Problem of Measurement}

"If you can not measure it, you can not improve it."

\section{Lord Kelvin}

In business and industry, quality is classically defined as "fitness for use" [23] or "conformance to requirements" [24]. Extrapolating from these standard business definitions of quality, "good" bone quality would mean a high level of resistance to fractures, or extrapolating even further [6], resistance to all factors accounting for fracture risk. One might then ask whether the likelihood of a fracture is solely dependent on bone strength, and accordingly, whether a fracture that resulted from mild or moderate trauma is a direct index of "bad" bone quality.

However, this kind of simplistic thinking ignores the fact that the etiology of any type of fracture among older adults is multifactorial, involving many extra-skeletal risk factors much stronger than the bone per se (measured by conventional BMD) [2533]. In this respect, one should recall that bone quality, by definition, cannot be but a bone-based trait only [2].

Even if the problems with the definition of bone quality could be solved, the fundamental problem with the bone quality concept is common to all new diagnostic tests [34]: the clinical value of a new diagnostic test depends on whether it improves patient outcomes beyond the outcome achieved with current diagnostic tests (here, the BMD and other well-known risk factors of fractures). As mentioned previously, it is true that highly increased bone turnover has been shown to improve the ability to predict some types of fractures independently of BMD $[8,17,18]$. However, so far we have little proof that the biochemical markers of bone turnover would be able to make a clinically relevant impact on the predictive ability of fracture independently of the well-known risk factors of fractures.

For example, incorporating a single non-skeletal risk factor (gait speed) into the predictive equation along with BMD and bone markers was shown to clearly diminish the fracture predictive ability of bone markers [17]. Thus, it remains quite utopian to envision that a pure bone-derived measure (e.g., BMD complemented by bone quality)

A NORMAL LOADING
DURING LOCOMOTION

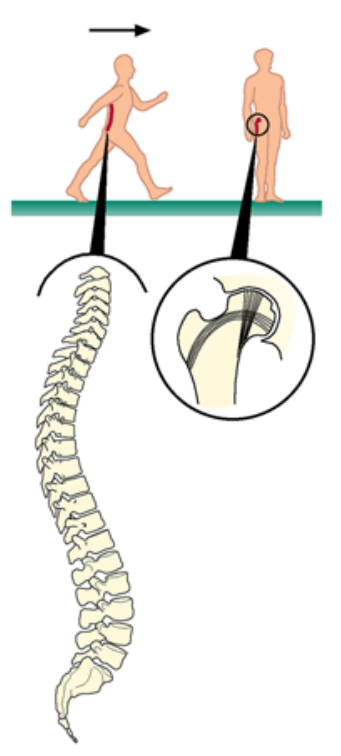

B

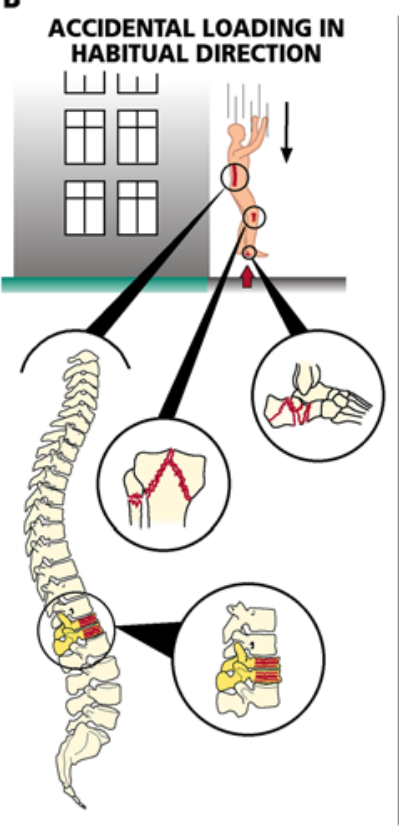

C

ACCIDENTAL LOADING FROM ABNORMAL DIRECTION
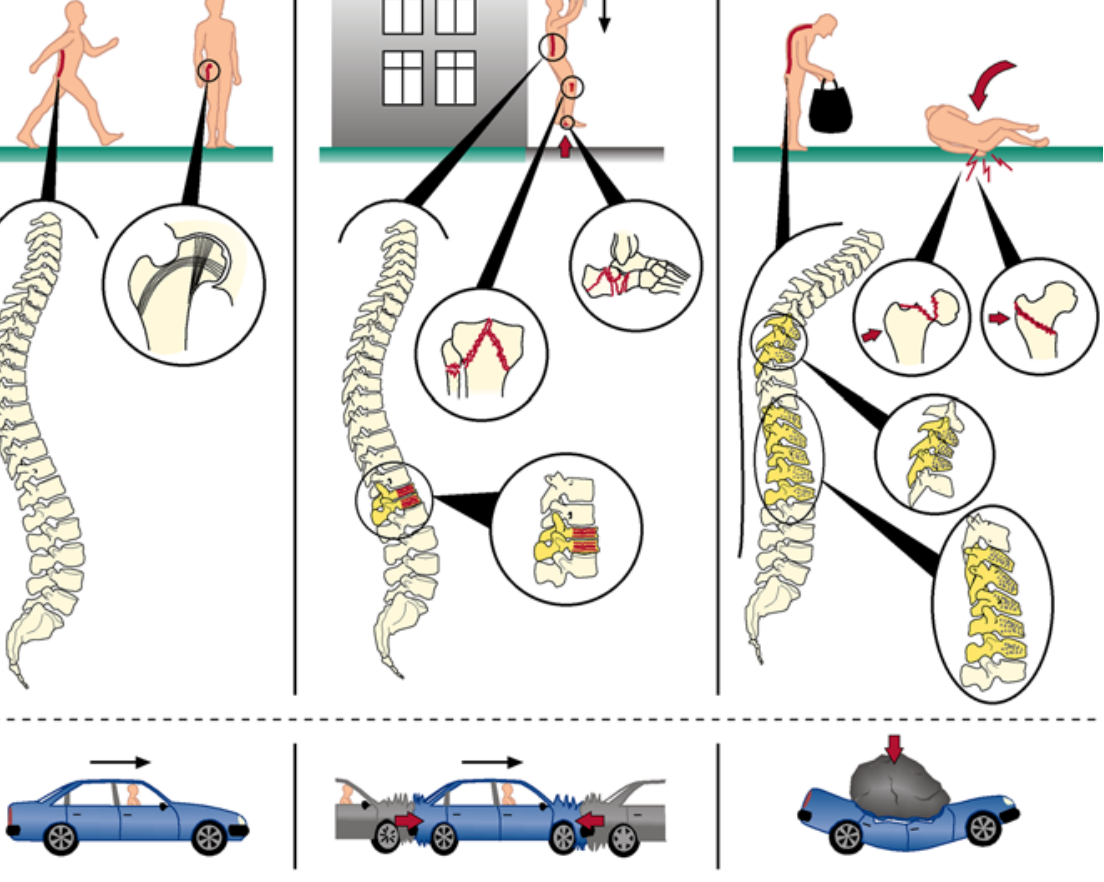

ANALOGY TO CARS

doi:10.1371/journal.pmed.0040027.g00

Figure 1. Bone Fractures, Car Accidents, and Direction of Impact

Analogous to automobiles designed to run on their wheels, the human skeleton is adapted to bipedal gait and the resulting habitual locomotive loadings (Figure 1A). In terms of safety, the design of cars is optimized to keep the driver and passengers in the cockpit intact during collisions from the typical directions of impact, the front or rear (Figure 1B). However, a similar or even smaller force can cause profound damage to the cockpit if it comes from an atypical (unforeseen) direction (Figure 1C). Analogously, the capacity of the skeleton to resist fractures during accidents is generally good when the loading caused by a traumatic incident is a moderate magnification of the loading experienced during habitual activities (i.e., within the inherent safety margin of bone), except in some cases where the incident force exceeds the bones' capacity to withstand the loading without structural failure (Figure 1B). In many cases of older adults' fractures, however, the incident loading in terms of direction, rate, and magnitude is essentially different from the loading that bones are adapted to (Figure 1C). Such cases can be caused, for example, by careless lifting of a shopping bag with straight knees $[42,48]$ or a sideways fall directly onto the hip $[26,30]$.

could ever cover all these extra-skeletal risk factors, too, and thus, predict solely the individual occurrence of fractures.

The prevailing understanding of bone quality supposes that the primary property of bones is their capacity to resist fractures. But this is a misconception. The human skeleton is basically a locomotive apparatus, which is continually adapting to habitual loadings [35,36] and is particularly fit for endurance activities [37]. Given the intrinsic locomotive function and the metabolic pressure to keep the skeleton light, there is a compromise between the bone's actual, functionally adequate strength and the maximum attainable strength. Bone has a great capacity to become substantially stronger through appropriate structural adaptations whenever needed to cope with increased functional demands [36]. However, while the skeleton can be reasonably well adapted to customary, functional loadings (Figure 1A), it is definitely not adapted to unusual loadings caused by occasional falls (or by other similar trauma-related events) [38]. Under such circumstances weak bone regions can become unduly stressed, possibly beyond their load-bearing capacity, initiating a fracture (Figure 1C). Fully in line with this fact, the relative risk of hip fracture can rise to up to 30 when the fall-induced impact directly hits the greater trochanter of the proximal femur $[26,28,39]$. It is thus 
quite understandable that the external loads from these non-habitual incidents cause most (up to $90 \%$ ) hip and wrist fractures [26,30,39] and also account for at least half of vertebral fractures [40-42].

\section{Conclusion}

In the end, the only reasonable mechanism by which any bone-targeted medication reduces fractures is through increasing the whole bone strength (one way or another). Accordingly, if we were able to accurately determine whole bone strength of individuals on antiresorptive therapy, the alleged discrepancy underlying the concept of bone quality would not exist. As the whole bone strength provides the ultimate measure of true bone quality, the paradox of osteoporosis appears to simply stem from our inherent inability to determine directly the actual bone strength of an individual in vivo. However, this inability cannot be taken as a justification to introduce an obscure and ill-defined concept such as bone quality.

If it really must be used, the term bone quality should refer only to the capacity of bones to withstand a wide range of loading without breakingthough we already have a proper term for such capacity, the whole bone strength. Therefore, we must strive to reliably estimate the whole bone strength in vivo. In this context, the new 3-dimensional imaging techniques of the actual bone structure and macroanatomy seem an interesting and promising option [43-47] that will hopefully help in solving the important clinical issue of bone fragility in the near future.

\section{Acknowledgments}

This study was supported by grants from the Medical Research Fund of Tampere University Hospital, the Research Council for Physical Education and Sports, Ministry of Education, and the AO Research Fund, Switzerland. The authors thank Dr. Jarkko Jokihaara for help with preparation of the figure.

\section{References}

1. Wallach S, Feinblatt JD, Carstens JH Jr, Avioli LV (1992) The bone "quality" problem. Calcif Tissue Int 51: 169-172.

2. Hernandez CJ, Keaveny TM (2006) A biomechanical perspective on bone quality. Bone 39: 1173-1181.

3. Kleerekoper M (2006) Osteoporosis prevention and therapy: Preserving and building strength through bone quality. Osteoporos Int 17: 1707-1715.
4. Seeman E, Delmas PD (2006) Bone qualityThe material and structural basis of bone strength and fragility. N Engl J Med 354: 2250_ 2261 .

5. Stokstad E (2005) Bone quality fills holes in fracture risk. Science 308: 1580.

6. Fyhrie DP (2005) Summary-Measuring "bone quality.” J Musculoskelet Neuronal Interact 5: 318-320.

7. Ettinger MP (2003) Aging bone and osteoporosis: Strategies for preventing fractures in the elderly. Arch Intern Med 163: 22372246.

8. Garnero P, Sornay-Rendu E, Claustrat B, Delmas PD (2000) Biochemical markers of bone turnover, endogenous hormones and the risk of fractures in postmenopausal women: The OFELY study. J Bone Miner Res 15: 15261536.

9. Faulkner KG (2000) Bone matters: Are density increases necessary to reduce fracture risk? J Bone Miner Res 15: 183-187.

10. Heaney RP (2003) Is the paradigm shifting? Bone 33: 457-465.

11. Melton LJ 3rd, Khosla S, Atkinson EJ, O'Fallon WM, Riggs BL (1997) Relationship of bone turnover to bone density and fractures. J Bone Miner Res 12: 1083-1091.

12. Riggs BL, Melton LJ 3rd (2002) Bone turnover matters: The raloxifene treatment paradox of dramatic decreases in vertebral fractures without commensurate increases in bone density. J Bone Miner Res 17: 11-14.

13. Sanders KM, Nicholson GC, Watts IJ, Pasco JA, Henry MJ, et al. (2006) Half the burden of fragility fractures in the community occur in women without osteoporosis. When is fracture prevention cost-effective? Bone 38 : 694-700.

14. Siris ES, Chen YT, Abbott TA, Barrett-Connor E, Miller PD, et al. (2004) Bone mineral density thresholds for pharmacological intervention to prevent fractures. Arch Intern Med 164: 1108-1112.

15. Stone KL, Seeley DG, Lui LY, Cauley JA, Ensrud K, et al. (2003) BMD at multiple sites and risk of fracture of multiple types: Longterm results from the Study of Osteoporotic Fractures. J Bone Miner Res 18: 1947-1954.

16. Garnero P, Delmas PD (2004) Contribution of bone mineral density and bone turnover markers to the estimation of risk of osteoporotic fracture in postmenopausal women. J Musculoskelet Neuronal Interact 4: 50-63.

17. Garnero P, Hausherr E, Chapuy MC, Marcelli C, Grandjean H, et al. (1996) Markers of bone resorption predict hip fracture in elderly women: The EPIDOS Prospective Study. J Bone Miner Res 11: 1531-1538.

18. Gerdhem P, Ivaska KK, Alatalo SL, Halleen JM, Hellman J, et al. (2004) Biochemical markers of bone metabolism and prediction of fracture in elderly women. J Bone Miner Res 19: 386-393.

19. Johnell O, Oden A, De Laet C, Garnero P, Delmas PD, et al. (2002) Biochemical indices of bone turnover and the assessment of fracture probability. Osteoporos Int 13: 523-526.

20. Bouxsein ML, Coan BS, Lee SC (1999) Prediction of the strength of the elderly proximal femur by bone mineral density and quantitative ultrasound measurements of the heel and tibia. Bone 25: 49-54.

21. Wilkin TJ, Devendra D (2001) Bone densitometry is not a good predictor of hip fracture. BMJ 323: 795-797.

22. Sievanen H (2000) A physical model for dualenergy X-ray absorptiometry-Derived bone mineral density. Invest Radiol 35: 325-330.

23. Juran JM, Gryna FM (1974) Juran's quality control handbook. Third edition. New York: Mcgraw-Hill.

24. Crosby PB (1979) Quality is free: The art of making quality certain. New York: Mcgraw-Hill.
25. Carter SE, Campbell EM, Sanson-Fisher RW, Gillespie WJ (2000) Accidents in older people living at home: A community-based study assessing prevalence, type, location and injuries. Aust N Z J Public Health 24: 633-636.

26. Hayes WC, Myers ER, Morris JN, Gerhart TN, Yett HS, et al. (1993) Impact near the hip dominates fracture risk in elderly nursing home residents who fall. Calcif Tissue Int 52: 192-198.

27. Lee SH, Dargent-Molina P, Breart G (2002) Risk factors for fractures of the proximal humerus: Results from the EPIDOS prospective study. J Bone Miner Res 17: 817-825.

28. Nevitt MC, Cummings SR (1993) Type of fall and risk of hip and wrist fractures: The study of osteoporotic fractures. The Study of Osteoporotic Fractures Research Group. J Am Geriatr Soc 41: 1226-1234.

29. Palvanen M, Kannus P, Parkkari J, Pitkajarvi T, Pasanen M, et al. (2000) The injury mechanisms of osteoporotic upper extremity fractures among older adults: A controlled study of 287 consecutive patients and their 108 controls. Osteoporos Int 11: 822-831.

30. Parkkari J, Kannus P, Palvanen M, Natri A, Vainio J, et al. (1999) Majority of hip fractures occur as a result of a fall and impact on the greater trochanter of the femur: A prospective controlled hip fracture study with 206 consecutive patients. Calcif Tissue Int 65: 183-187.

31. Robinovitch SN, Inkster L, Maurer J, Warnick B (2003) Strategies for avoiding hip impact during sideways falls. J Bone Miner Res 18: 1267-1273.

32. Schwartz AV, Kelsey JL, Sidney S, Grisso JA (1998) Characteristics of falls and risk of hip fracture in elderly men. Osteoporos Int 8: 240-246.

33. Wei TS, Hu CH, Wang SH, Hwang KL (2001) Fall characteristics, functional mobility and bone mineral density as risk factors of hip fracture in the community-dwelling ambulatory elderly. Osteoporos Int 12: 1050-1055.

34. Lord SJ, Irwig L, Simes RJ (2006) When is measuring sensitivity and specificity sufficient to evaluate a diagnostic test, and when do we need randomized trials? Ann Intern Med 144 $850-855$.

35. Frost HM (2003) Bone's mechanostat: A 2003 update. Anat Rec 275A: 1081-1101.

36. Ruff C, Holt B, Trinkaus E (2006) Who's afraid of the big bad Wolff?: "Wolff's law" and bone functional adaptation. Am J Phys Anthropol 129: 484-498.

37. Bramble DM, Lieberman DE (2004) Endurance running and the evolution of Homo. Nature 432: 345-352.

38. Currey JD (2003) How well are bones designed to resist fracture? J Bone Miner Res 18: 591-598.

39. Greenspan SL, Myers ER, Kiel DP, Parker RA, Hayes WC, et al. (1998) Fall direction, bone mineral density, and function: Risk factors for hip fracture in frail nursing home elderly. Am J Med 104: 539-545.

40. Cooper C, Atkinson EJ, Kotowicz M, O'Fallon WM, Melton LJ 3rd (1992) Secular trends in the incidence of postmenopausal vertebral fractures. Calcif Tissue Int 51: 100-104.

41. Cooper C, Atkinson EJ, O'Fallon WM, Melton LJ 3rd (1992) Incidence of clinically diagnosed vertebral fractures: A population-based study in Rochester, Minnesota, 1985-1989. J Bone Miner Res 7: 221-227.

42. Myers ER, Wilson SE (1997) Biomechanics of osteoporosis and vertebral fracture. Spine 22: 25S-31S.

43. Carpenter RD, Beaupre GS, Lang TF, Orwoll ES, Carter DR (2005) New QCT analysis approach shows the importance of fall orientation on femoral neck strength. J Bone Miner Res 20: 1533-1542.

44. Cheng X, Li J, Lu Y, Keyak J, Lang T (2007) 
Proximal femoral density and geometry measurements by quantitative computed tomography: Association with hip fracture. Bone 40: 169-174

45. Khosla S, Riggs BL, Atkinson EJ, Oberg AL McDaniel LJ, et al. (2006) Effects of sex and age on bone microstructure at the ultradistal radius: A population-based noninvasive in vivo assessment. J Bone Miner Res 21: 124-131.

46. Lang T, Augat P, Majumdar S, Ouyang X,

Genant HK (1998) Noninvasive assessment of bone density and structure using computed tomography and magnetic resonance. Bone 22 149S-153S.

47. Riggs BL, Melton LJ 3rd, Robb RA, CampJJ, Atkinson EJ, et al. (2006) Population-based analysis of the relationship of whole bone strength indices and fall-related loads to age- and sex-specific patterns of hip and wrist fractures. J Bone Miner Res 21: 315-323.

48. Duan Y, Seeman E, Turner CH (2001) The biomechanical basis of vertebral body fragility in men and women. J Bone Miner Res 16: 2276-2283.

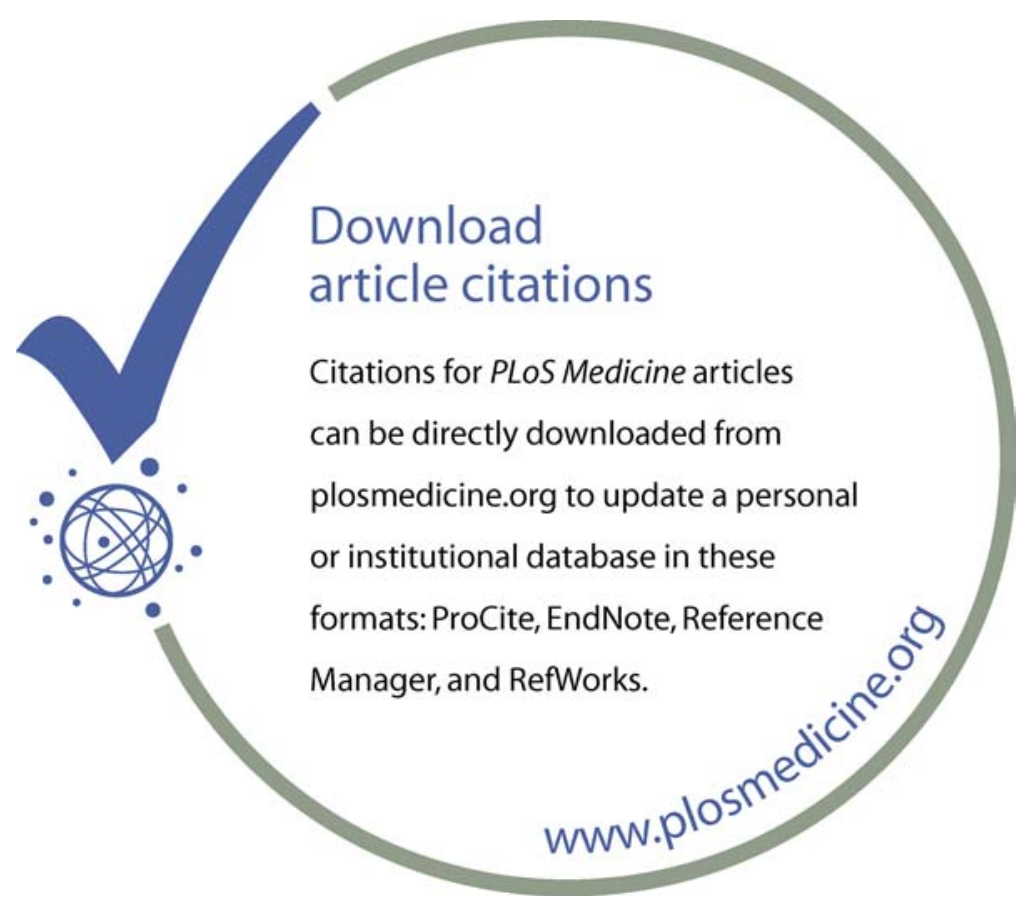

